\title{
ГОСУДАРСТВЕННАЯ ПОДДЕРЖКА РАЗВИТИЯ НАУЧНЫХ ИССЛЕДОВАНИЙ В УНИВЕРСИТЕТАХ И ИХ УЧАСТИЯ В НАУЧНО-ТЕХНОЛОГИЧЕСКОМ РАЗВИТИИ *
}

\author{
(C) 2021 Рыжая Анна Андреевна
}

кандидат экономических наук, доцент

Сибирский государственный университет науки и технологий имени академика М. Ф. Решетнева, Россия, Красноярск

E-mail: ryzhaya@sibsau.ru

\section{(C) 2021 Шпак Анастасия Сергеевна}

кандидат экономических наук, доцент

Сибирский государственный университет науки и технологий имени академика М.Ф.Решетнева, Россия, Красноярск

E-mail: ya1604@yandex.ru

\section{(c) 2021 Беляков Сергей Андреевич}

кандидат экономических наук, доцент

Сибирский государственный университет науки и технологий имени академика М.Ф. Решетнева, Россия, Красноярск

E-mail: belyakovserg@mail.ru

В статье показана роль университетов в научно-технологическом развитии в России. Рассмотрены меры, принимаемые государством по развитию университетской науки и участию вузов в научно-технологическом развитии. Проанализированы нормативные документы по развитию университетской науки. Выделены причины и сдерживающие факторы развития вузовской науки, а также пути по их устранению.

Ключевые слова: научно-технологическое развитие, научные исследования, государственная поддержка научных исследований, университетская наука.

В реализации Стратегии научнотехнологического развития Российской Федерации важная роль принадлежит высшим учебным заведениям страны. Согласно Федеральному закону от 29.12.2012 № 273-ФЗ «Об образовании» основным назначением образовательных учреждений высшего профессионального образования является образовательная и научная деятельность. Для осуществления научной деятельности высшие учебные заведения могут иметь в своей структуре различные подразделения: институты, центры, научноисследовательские подразделения, лаборатории, конструкторские бюро, а в штатном расписании могут предусматриваться должности научных сотрудников. Образовательные организации высшего образования, являющиеся бюджетными или автономными учреждениями, вправе быть учредителями хозяйственных обществ и хозяйственных товариществ (малых инновационных предприятий), деятельность которых заключается в практическом применении (внедрении) результатов интеллектуальной деятельности, исключительные права на которые принадлежат указанным организациям.

Отличительными особенностями университетской науки, определяющей возможности участия университетов в научно-технологическом развитии, являются:

- сочетание фундаментальных и прикладных исследований;

- междисциплинарность;

- более тесное взаимодействие с промышленными предприятиями по сравнению с научными организациями;

- взаимосвязь научной и образовательной деятельности, позволяющая готовить специалистов по перспективным направлениям техноло-

* Исследование выполнено при финансовой поддержке РФФИ в рамках научного проекта № 19010-00355. 
гического развития;

- широкие возможности отбора молодых талантливых кадров из студентов и их вовлечения в научную деятельность;

- развитая система подготовки научных кадров (кандидатов и докторов наук) по широкому спектру научных специальностей, связанная с проведением исследований по актуальным направлениям научно-технологического развития;

- более широкие возможности по сравнению с научными организациями для создания малых инновационных предприятий, коммерциализирующих результаты научных исследований;

- широкие возможности развития научного потенциала, его перенастройки под новые задачи;

- преобладающее стремление многих университетов участвовать в решении задач научно-технологического развития;

- ведущая роль университетской науки в регионах со слабо развитой сетью научноисследовательских организаций.

Осуществление научной деятельности, использование ее результатов и научных знаний в учебном процессе, вовлечение в научную работу студентов и аспирантов является важнейшей качественной характеристикой современного университета. Однако в отличие от научных организаций научно-исследовательская деятельность до сих пор остается в российских вузах второстепенной по сравнению с образовательной деятельностью, что выражается в структуре кадрового потенциала и объемах финансирования образовательной и научной деятельности [3, с. 31]. По данным государственной статистики в 2019/20 гг. профессорско-преподавательский состав вузов России (без внешних совместителей) составлял 229300 человек, из них с ученой степенью доктора наук - 35800 человек, кандидата наук - 131800 человек. При этом в исследованиях и разработках было задействовано 74215 человек (32,3\%). Из 167600 человек ППС с учеными степенями в качестве исследователей выполняли работу 48429 человек $(28,9 \%)$. Доля сектора высшего образования в общем объеме затрат на науку составляла 10,6\%., что ниже аналогичного показателя большинства ведущих стран: во Франции - 20,3\%, Германии - 17,3\%, США - 12,3\%, Японии - 11,7\%. Вместе с тем, тренды последних лет позволяют ожидать, что
Россия со временем сможет приблизиться к таким значениям. За период 2010-2019 гг. внутренние затраты на исследования и разработки в секторе высшего образования выросли в 1,5 раза, достигнув 120,6 млрд. руб. (в постоянных ценах) [9].

Таким образом, в высших учебных заведениях сосредоточен значительный нереализованный потенциал, который может быть использован в научно-технологическом развитии страны.

Меры, принимаемые государством по развитию университетской науки и участию вузов в научно-технологическом развитии.

В постсоветский период реализация государственной политики по развитию вузовской науки началась с поддержки интеграции высшего образования и академической науки. В 1996 г. была инициирована Президентская целевая программа «Государственная поддержка интеграции высшего образования и фундаментальной науки на 1997-2000 гг.». Ее основной целью было развитие сотрудничества вузов с академическими организациями в области обучения и фундаментальных исследований путем создания учебно-научных центров. Поддержка интеграции вузов и академических организаций продолжилась с утверждением Правительством РФ федеральной целевой программы «Интеграция науки и высшего образования России на 2002-2006 гг.». Программа предусматривала мероприятия по: обеспечению взаимодействия организаций науки и высшего образования и развитию новых форм научно-образовательной деятельности; привлечению талантливой молодежи в сферу науки, высшего образования, инновационную деятельность; развитию информационных технологий в научном и образовательном процессах; улучшению материальнотехнического обеспечения интеграционного развития науки и высшего образования [12].

Параллельно с предыдущими интеграционными программами с 1998 года по совместной инициативе Министерства образования и науки Российской Федерации и Американского фонда гражданских исследований и развития (CRDF) при паритетном финансировании реализовывалась Программа «Фундаментальные исследования и высшее образование». Программа была направлена на поддержку естественнонаучных исследований, проводимых в вузах России, путем создания в них научно-образовательных центров принципиально новой модели. Всего 
было создано 16 таких центров, каждый из которых получил гарантированное («базовое») финансирование в размере около 1,5 млн. долларов на 5 лет. В общей сложности на поддержку центров в 1998-2005 годах было выделено 26,6 миллиона долларов. Модель НОЦ была признана успешной.

Существенную роль в развитии научных исследований в вузах оказало их участие в реализации Федеральных целевых программ:

- ФЦП «Исследования и разработки по приоритетным направлениям развития научнотехнологического комплекса». Целью программы было развитие научно-технологического потенциала России по приоритетным направлениям развития науки, технологий и техники.

- ФЦП «Научные и научно-педагогические кадры инновационной России». Цель программы - создание условий для эффективного воспроизводства научных и научно-педагогических кадров и закрепления молодежи в области науки, образования и высоких технологий, сохраняя преемственность поколений в науке и образовании.

В 2009 г. поддержка вузовской науки стала одним из важных направлений политики государства. Министерством образования и науки РФ в лице министра А.А.Фурсенко были официально объявлены мотивы выделения вузовского сектора науки в особую, «приоритетную» категорию: во-первых, правительство поставило цель - создание в науке конкурентной среды, а вузы с их относительно слабой научной базой не могут конкурировать с академическими научными организациями; во-вторых, усиление науки в вузах необходимо для повышения качества образования в целом и в частности для привлечения в сферу исследований и разработок лучше подготовленных к научной работе молодых кадров; в-третьих, было осознано, что профессор, не занимающийся научными исследованиями, не может дать современных знаний студентам и тем более аспирантам [25]. Как отмечает И.Дежина, в правительстве стала популярной англо-саксонская модель развития высшей школы, согласно которой основной объем фундаментальных исследований проводится в университетах. K тому же были политические причины, объясняющие переориентацию финансовых средств на поддержку вузовской науки, связанные с долгим противостоянием Президиума РАН и Министерства образования и науки по целому ряду вопросов развития науки [21].

Государственная политика по поддержке науки в высших учебных заведениях реализовалась путем присвоения отдельным университетам специальных статусов. Федеральным законом от 10.11.2009 № 259-ФЗ Московский и Санкт-Петербургский государственные университеты (МГУ и СПбГУ) получили особый статус «уникальных научно-образовательных комплексов». Федеральным законом от 10.02.2009 № 18-ФЗ установлен статус федеральных университетов и национальных исследовательских университетов. Федеральные университеты создаются в форме автономного учреждения, являются ведущими научными и методическими центрами, осуществляют фундаментальные и прикладные научные исследования по широкому спектру наук, обеспечивают интеграцию науки, образования и производства, в том числе путем доведения результатов интеллектуальной деятельности до практического применения. В настоящее время в стране создано 10 федеральных университетов.

Категория «национальный исследовательский университет» устанавливается Правительством Российской Федерации по результатам конкурсного отбора программ развития вузов, одинаково эффективно реализующих образовательные программы высшего профессионального и послевузовского профессионального образования и выполняющих фундаментальные и прикладные научные исследования по широкому спектру наук. При принятии решения о введении данной категории вузов намечалось, что они должны не просто эффективно вести научную и образовательную деятельность, но и генерировать знания, обеспечивать внедрение разработанных технологий в экономику, иметь высокоэффективную систему подготовки магистров и кадров высшей квалификации, а также развитую систему программ послевузовской переподготовки и повышения квалификации. Категория «национальный исследовательский университет» присвоена 29 вузам страны.

Позднее была выделена еще одна категория вузов - опорные университеты. Формирование сети опорных региональных университетов было предусмотрено в Федеральной целевой программе развития образования, утвержденной постановлением Правительства РФ от 23.05.2015 № 497. Следует подчеркнуть, что с самого начала не был четко определен статус опорных 
университетов, их место в системе высшего образования, какие новые задачи должно решать высшее учебное заведение в образовательной и научной деятельности став опорным университетом. Высказывалась общая идея выделить вузы, на которые можно будет опереться в региональном развитии [6]. При этом после проведения конкурсного отбора предусматривалось дополнительное финансирование опорных университетов. На настоящий момент проведено два этапа конкурсного отбора, по итогам которых выделено 33 опорных университета в 32 субъектах Российской Федерации (2016 г. - 11 вузов, 2017 г. - 22 вуза). Отличительными особенностями этапов явилось то, что на первом этапе в числе основных требований к участникам было их реорганизация путем присоединения вуза - партнера, а на втором этапе данное требование было снято. Объем федеральной поддержки опорных университетов составил в 2016 г. - 1,2 млрд. руб., в 2017 г. - 1,9 млрд. руб. [21]. Новая программа развития опорных университетов, озвученная руководством Министерства науки и высшего образования РФ в 2020 г., предполагает разделить их на два типа: региональные и отраслевые с более четкой формулировкой стоящих перед ними задач [22].

Новый этап осуществления мер государственной поддержки вузов, направленных на развитие науки и участие университетов в реализации задач научно-технологического развития страны, начался после утверждения в декабре 2016 г. Президентом РФ «Стратегии научно-технологического развития Российской Федерации» и последовавшей за этим разработкой и утверждением Государственной программы «Научно-технологическое развитие Российской Федерации» и Национального проекта «Наука» (позднее «Наука и университеты»).

В октябре 2017 г. было принято постановление Правительства РФ от 16.10.2017 № 1251 «Об утверждении Правил предоставления субсидии из федерального бюджета на оказание государственной поддержки центров Национальной технологической инициативы на базе образовательных организаций высшего образования и научных организаций и Положения о проведении конкурсного отбора на предоставление грантов на государственную поддержку центров Национальной технологической инициативы на базе образовательных организаций высшего образования и научных организаций». Цен- тры компетенций создаются как структурные подразделения вуза для осуществления комплексного развития сквозных технологий НТИ совместно с иными образовательными и научными организациями, промышленными предприятиями.

В соответствии с Национальным проектом «Наука» в рамках Федерального проекта «Развитие кадрового потенциала в сфере исследований и разработок» было предусмотрено создание не менее 900 новых научных лабораторий, руководителями не менее 30\% которых должны быть молодые перспективные исследователи. Созданная Министерством науки и высшего образования РФ Комиссия по отбору научных проектов, выполняемых коллективами научных лабораторий образовательных организаций высшего образования в мае 2019 г. утвердила критерии и порядок отбора научных проектов вузов для создания новых лабораторий.

В августе 2020 г. было принято постановление Правительства РФ от 01.08.2020 № 1156 «Об утверждении Правил предоставления грантов в форме субсидий из федерального бюджета на реализацию проектов по созданию и развитию инжиниринговых центров на базе образовательных организаций высшего образования и научных организаций».

Особое значение для решения задачи широкого привлечения университетов к реализации Стратегии научно-технологического развития РФ имеет инициированная в июне 2020 г. Министерством науки и высшего образования РФ Программа стратегического академического лидерства «Приоритет 2030». В основу концепции Программы положены Поручения Президента РФ от 28.09.2020 № Пр-1726ГС: «при разработке Программы стратегического академического лидерства предусмотреть:

1) развитие университетов, реализующих прорывные научные исследования, создающих наукоемкую продукцию и технологии, для социально-экономического развития территорий, укрепления кадрового и научнотехнологического потенциала организаций реального сектора экономики и социальной сферы;

2) формирование механизмов интеграции университетов и научных организаций и их кооперации с организациями реального сектора экономики». По словам министра науки и высшего образования В.Н.Фалькова, в отличие от 
предыдущих программ развития российских вузов, данная программа нацелена на национальные интересы. Меняется целеполагание: важны не рейтинги, не наукометрические показатели, а в данном случае в центре внимания всех университетов должны быть национальные цели развития. Программа прошла всестороннее обсуждение с представителями университетского и академического сообщества, рассмотрена на Российском союзе ректоров и заседании Президиума Российской академии наук.

В декабре 2020 г. Правительство РФ приняло распоряжение от 31.12.2020 № 3697-р, в котором решило «согласиться с предложением Минобрнауки России, согласованным с Минэкономразвития России и Минфином России, о реализации в 2021-2030 годах программы стратегического академического лидерства (программа «Приоритет-2030»), направленной на поддержку программ развития образовательных учреждений высшего образования путем предоставления грантов в виде субсидий на поддержку указанных программ, реализуемых, в том числе с научными организациями и обеспечивающих подготовку кадров по приоритетным направлениям научно-технологического развития РФ, отраслей экономики и социальной сферы, развитие и реализацию прорывных научных исследований и разработок, а также внедрение высоких технологий в экономику и социальную сферу». Распоряжением Правительства РФ органам государственной власти субъектов РФ рекомендовано рассмотреть возможность оказания дополнительной поддержки образовательным организациям, получающим поддержку по программе «Приоритет-2030», с внесением при необходимости изменений в соответствующие государственные программы субъектов Российской Федерации.

В мае 2021 г. Правительство РФ приняло постановление от 13.05.2021 № 729 «О мерах по реализации программы стратегического академического лидерства «Приоритет-2030». Данным постановлением Правительство РФ утвердило Правила проведения отбора образовательных организаций высшего образования и Правила предоставления грантов в форме субсидий из федерального бюджета на оказание поддержки программ развития образовательных организаций высшего образования. Правилами проведения отбора вузов определены [13]:

- критерии, при соответствии которым вузы получают допуск к участию в программе «Приоритет-2030». При проведении отбора Комиссия министерства определяет вузы - участники программы и вузы - кандидаты на участие в программе. Всем отобранным вузам предусмотрено выделение базовой части гранта;

- направления и условия предоставления участникам программы специальных частей гранта, среди которых выделены: а) исследовательское лидерство - проведение прорывных научных исследований и создание наукоемкой продукции и технологий, наращивание кадрового потенциала сектора исследований и разработок и б) территориальное и (или) отраслевое лидерство - социально-экономическое развитие территорий, укрепление кадрового и научно-технологического потенциала организаций реального сектора экономики и социальной сферы;

- требования к программам развития университетов.

Программы развития университетов должны быть направлены на повышение вклада вузов в достижение национальных целей развития Российской Федерации на период до 2030 года, сбалансированное пространственное развитие страны, обеспечение доступности качественного высшего образования в регионах РФ. Рекомендованы отдельные мероприятия, среди которых особо следует выделить:

- подготовка кадров для приоритетных направлений научно-технологического развития;

- разработка и внедрение прорывных научных исследований и разработок;

- внедрение высоких технологий в экономику и социальную сферу, коммерциализация результатов интеллектуальной деятельности и трансфер технологий;

- развитие кадрового потенциала системы высшего образования и сектора исследований и разработок, привлечение в вузы ведущих ученых и специалистов - практиков;

- реализация мер по совершенствованию научно-исследовательской деятельности в магистратуре, аспирантуре и докторантуре;

- объединение с университетами и научными организациями;

- цифровая трансформация университетов и научных организаций;

- вовлечение обучающихся в научноисследовательские, опытно-конструкторские и инновационные работы и др. 
В программах развития университетов дополнительно может быть предусмотрено осуществление мероприятий с образованием консорциумов - объединений, в том числе без образования юридического лица, с другими университетами, научными организациями и при необходимости с иными организациями на основании договоров о сотрудничестве.

Минимальный размер базовой части гранта составляет 100 млн. руб. в год. Размер специальной части гранта рассчитывается по итогам оценки программы университета Советом по поддержке программ развития образовательных организаций высшего образования в рамках реализации программы стратегического академического лидерства «Приоритет-2030» (утвержден постановлением Правительства РФ от 13.05.2021 № 730) $[13,14,16]$. Советом рекомендован предельный размер специальной части гранта на 2021 г. - 170,3 млн. руб., на 2022 г. 824,2 млн. руб.

В октябре 2021 г. подведены итоги конкурса. Как заявил министр науки и высшего образования В.Н.Фальков, господдержку получат 106 российских вузов. Базовую часть гранта 100 млн. руб. получат все вошедшие в программу университеты, специальную часть гранта получат 18 университетов по направлению «исследовательское лидерство» и 36 вузов по направлению «территориальное или отраслевое лидерство» [20]. Реализация программы «Приоритет-2030» будет происходить в два этапа: 2021-2025 гг. и 2025-2030 гг. По итогам первого этапа в 2025 году намечено провести ротацию не меньше $1 / 3$ вузов должны выйти из программы и предоставить возможность участия в программе другим вузам [10].

Причины и сдерживающие факторы развития вузовской науки, и возможные пути их устранения.

При огромных усилиях по развитию университетской науки, принимаемых государством в последнее время, имеется целый ряд причин и сдерживающих факторов, мешающих эффективному и в полном объеме решению поставленных государством задач по участию университетов в научно-технологическом развитии страны и регионов. Среди них, особо необходимо выделить следующие:

1) кадровые проблемы обеспечения научно-исследовательской и инновационной деятельности вузов;

2) отсутствие необходимой современной материально-технической базы для проведения передовых исследований;

3) проблемы организации научных исследований и разработок, слабая связь и взаимодействие с академическими научными организациями, недостаточный уровень руководства научно-исследовательской деятельностью;

4) неготовность многих промышленных предприятий к активному взаимодействию с университетами и научными организациями, недостаточно эффективная система государственной поддержки и стимулирования исследовательской и инновационной активности предприятий;

5) неразвитость региональной системы государственной поддержки и стимулирования научной и инновационной деятельности вузов;

6) несовершенная система стратегического планирования и координации научных исследований и разработок по приоритетным направлениям научно-технологического развития.

Важнейшим условием развития университетской науки и участия вузов в научнотехнологическом развитии является наличие кадров, обладающих необходимыми компетенциями, которых возможно привлечь к выполнению научных исследований и разработок по выбранным вузом научным направлениям, соответствующим приоритетам Стратегии научно-технологического развития страны, профильным отраслевым и региональным технологическим приоритетам. Как отмечают многие авторы исследований данной проблемы, серьезным препятствием для привлечения действующего профессорско-преподавательского состава (ППС) вуза к проведению научных исследований является чрезмерная учебная нагрузка преподавателей [5, 8, 19, 23]. Данная проблема в России возникла давно. На размер учебной нагрузки непосредственно влияет соотношение численности ППС и контингента студентов. В 1980-х гг. в ведущих университетах и многопрофильных технических вузах, где активно велась научноисследовательская деятельность, коэффициент составлял 1:4-1:8, в остальных вузах $-1: 12$. В конце 1990-х гг. Постановлением Правительства РФ от 17.06.1998 № 600 было установлено нормативное соотношение численности в размере 1:10 (расчет осуществлялся по сумме контрольных цифр приема в течение всего срока обучения) [1]. С введением системы эффективного контракта с научно-педагогическими 
работниками образовательных организаций высшего образования и нормативного подушевого финансирования образовательных программ высшего образования Распоряжением Правительства РФ от 30.04.2014 № 722-р была утверждена дорожная карта постепенного увеличения нормативов: 2014 г. - 1:10,5; 2015 г. 1:10,7; 2016 г. - 1:11,1; 2017 г. - 1:11,6; 2018 г $1: 12$ [17]. В том же году приказом Министерства образования и науки РФ от 22.12.2014 г. № 1602 был установлен верхний предел учебной нагрузки для ППС вузов в объеме, не превышающим 900 часов в учебном году [15]. Вместе с тем, администрации вузов все чаще считают 900 часов не максимально допустимой, а обязательной нагрузкой [8].

Рассматривая нагрузку преподавателей вузов, какой она должна быть в соответствии с нормативными документами, Е.Н.Ковтун и С.Е.Родионова отмечают, что средняя загруженность преподавателей вузов сегодня составляет 850 аудиторных часов, это - то время, которое преподаватель должен проводить со студентами [7]. Из общей годовой нагрузки преподавателя 1580 часов, оставшееся внеаудиторное время (вторая половина нагрузки преподавателя) распределяется на учебно-методическую, организационнометодическую, воспитательную и научноисследовательскую работу. В настоящее время в России не определены типовые нормы затрат на эти виды работ, отсутствует разработанная методика расчета оптимальной нагрузки преподавателей. Поэтому вузы эти нормы определяют самостоятельно и, как показывает практика, далеко не в пользу научной работы. Так, в некоторых вузах на научные исследования выделяется не более 100 часов. Е.Н. Ковтун и С. Е. Родионова делают вывод, что назрела очевидная необходимость обоснованного планирования и оценивания трудозатрат преподавателя по всем формам выполняемой работы [7].

Большой объем учебной нагрузки не позволяет преподавателям плодотворно заниматься научной работой. Как отметил в своем выступлении на заседании Совета по науке и образованию при Президенте РФ 23.06.2014 г. зам. председателя Дальневосточного отделения РАН, директор Института биологии моря, академик РАН Андрей Адрианов, «современный преподаватель должен заниматься наукой и быть в курсе новейших достижений в своей области. Однако хроническая перегрузка учебными часами, осо- бенно в региональных вузах, вынуждает преподавателей с нагрузкой 800-900 часов, а молодых преподавателей с нагрузкой до 1000 часов становиться ретрансляторами, то есть пересказывать учебники. Им крайне сложно физически полноценно заниматься научными исследованиями, следить за последними достижениями науки, писать и выигрывать гранты, вовлекаться в международные научные проекты, выстраивать сотрудничество с промышленными предприятиями» [5]. Следует отметить, что сохраняющаяся в стране длительное время подобная ситуация ведет фактически к деградации научного потенциала вуза, отражающаяся на качестве подготовки специалистов, формировании тематики и снижении уровня диссертационных исследований, не способности выполнять научные исследования по прорывным направлениям научно-технологического развития.

Важным в данном случае представляется сравнение с нормативами учебной нагрузки преподавателей вузов за рубежом. А.А.Яшин и М.Н.Струкова отмечают, что пример зарубежных университетов демонстрирует нам средний размер учебной нагрузки примерно в 300-350 часов в год при средней доле аудиторной нагрузки в 150-200 часов на преподавателя. Это позволяет профессорско-преподавательскому составу активно заниматься исследованиями и участвовать в грантовых программах [24]. Во Франции нормы нагрузки штатного преподавателя высшей школы определяются постановлениями Правительства Французской Республики. В частности, в пределах ставки максимальное количество часов лекционных занятий составляет 128 часов, минимальное - 42 часа. Как указано в Постановлении Правительства, учебная деятельность должна оставлять каждому преподавателю значительное время для своей исследовательской деятельности [18].

Учитывая, что штатный профессорскопреподавательский состав университета формирует основной кадровый состав намечаемых к выполнению научно-исследовательских работ, данная проблема требует научно обоснованного ее решения на государственном уровне. Во-первых, требуется нормативно закрепить научные исследования как обязательный вид основной деятельности преподавателя, в том числе, и как научного работника, дифференцировав нормативы затрат в зависимости от занимаемой штатной должности (рассматривать в первой полови- 
не нагрузки преподавателя с соответствующими формами отчетности). Во-вторых, уточнить состав видов деятельности, учитываемых в общей нагрузке преподавателя (второй ее половине) и разработать типовые нормы затрат. В-третьих, разработать методику расчета оптимальной нагрузки преподавателя, с учетом занимаемой штатной должности дифференцировав для разных типов высших учебных заведений.

Важным условием, обеспечивающим возможность проведения научных исследований, особенно по приоритетным направлениям научно-технологического развития, формирующегося нового технологического уклада, является наличие передовой, мирового уровня материально-технической базы. В настоящее время у большинства вузов, особенно региональных, такой базы нет. Поэтому включаясь в реализацию научно-технических программ вузу необходимо наряду с кадровой проблемой решать и задачи формирования соответствующей материально-технической базы. В качестве вариантов могут рассматриваться: возможность использования оборудования Центров коллективного пользования, кооперация с другими университетами и научными организациями, приобретение недостающего оборудования за счет средств финансируемой программы НИР.

Активное развитие научных исследований по программе стратегического академического лидерства «Приоритет - 2030» требует совершенствования организации научных исследований и разработок в вузе и, прежде всего, создания научных подразделений, выполняющих научные исследования по закрепленной тематике. В настоящее время в рамках национального проекта «Наука и университеты» при государственной поддержке со стороны Министерства науки и высшего образования РФ осуществляется создание в вузах лабораторий по актуальной научной тематике. Кроме того, представляется актуальным также создание проблемных академических и отраслевых лабораторий. Главным принципом развития вузовского сектора науки, как считают В.В.Иванов и Г.Г.Малинецкий, должно быть взаимодействие с академическим и отраслевыми секторами науки. Научная база университетов должна формироваться путем создания на их территории отраслевых лабораторий, финансируемых непосредственно отраслями, государственными корпорациями или крупными научно-производственными органи- зациями, а также академических проблемных лабораторий для проведения фундаментальных исследований по программам государственных академий наук. При этом финансирование академических проблемных лабораторий должно осуществляться целевым образом из федерального бюджета на конкурсной основе на основе подачи совместной заявки университетом и академическим институтом. В этом случае будут устранены административные барьеры и неоправданная конкуренция между университетской и академической наукой, будет расширено участие ученых в образовательном процессе, а преподавателей и студентов в реальных научных исследованиях. Для обеспечения качественной организации научных исследований в университетах целесообразно ввести в вузы научных руководителей из числа ведущих академических ученых [4, с. 277-278]. Следует подчеркнуть, что создание проблемных академических лабораторий, прежде всего, необходимо в исследовательских университетах, а отраслевых лабораторий - в опорных университетах. Для реализации данного предложения необходимо принятие специального постановления Правительства Российской Федерации, определяющего порядок создания проблемных и отраслевых лабораторий и условия организации их деятельности.

Учитывая, что в программе Стратегического академического лидерства «Приоритет - 2030» опорным университетам отводится особая роль в решении задач научно-технологического развития страны и регионов, важным является их тесная взаимосвязь и взаимодействие с отраслевыми и региональными органами исполнительной власти. Критерии участия вуза в Программе «Приоритет 2030» предусматривают наличие у органа государственной власти субъекта Российской Федерации, на территории которого находится университет, и (или) профильного федерального органа исполнительной власти, обязательства по его исполнению, а также (или) соответствующая системообразующая организация для оказания дополнительной финансовой поддержки реализации программы развития университета. Чтобы данный механизм поддержки опорных университетов работал необходимо законодательное закрепление прав федеральных органов исполнительной власти, государственных корпораций, органов власти субъектов РФ осуществлять такую поддержку. 
Для активного взаимодействия университетов с частными промышленными предприятиями необходимо совершенствование механизма государственной поддержки и стимулирования инновационной и исследовательской активности предприятий, как это принято во всех ведущих зарубежных странах [2].

Опорные университеты, участвующие в Программе, должны обеспечить: подготовку кадров для приоритетных направлений научнотехнологического развития субъектов РФ, отраслей экономики и социальной сферы; проведение научных исследований и разработок, создание и внедрение высоких технологий в экономику и социальную сферу; коммерциализацию результатов интеллектуальной деятельности и трансфер технологий. Это предполагает, что сами субъекты РФ должны проводить активную политику и принимать непосредственное участие в обеспечении научно-технологического развития региона. Об этом говорится в Основах государственной политики регионального развития Российской Федерации на период до 2025 года, утвержденных Указом Президента РФ от 16.01.2017, определяющими цель государственной политики регионального развития: обеспечение устойчивого экономического роста и научно-технологического развития регионов [11]. Вместе с тем, до сих пор не определены четко полномочия субъектов РФ в научнотехнологическом развитии, вследствие чего не сформирована во многих регионах соответствующая организационная структура в органах исполнительной власти, а также в решении данных проблем не участвуют и органы законодательной власти.

Еще одной важной проблемой участия университетов в научно-технологическом развитии является координация тематики научных исследований, проводимых университетами. Президент Российской академии наук академик Сергеев А. М. отмечает: «нескоординированность научных исследований - одна из главных проблем развития страны» [21]. Практически всю тематику проводимых исследований университеты формируют сами. На этом построена политика Министерства науки и высшего образования РФ при организации программ под- держки научных исследований в высшей школе, в том числе и Программа «Приоритет-2030». При принятии решения о финансировании научных исследований проверяется в основном их соответствие приоритетным направлениям и критическим технологиям. С одной стороны, это способствует развитию университетской науки, но в то же время, отсутствие координации на государственном уровне не позволяет комплексно решать задачи реализации приоритетных направлений научно-технологического развития, приводит к дублированию исследований и распылению ограниченных государственных бюджетных средств. В связи с этим, для концентрации усилий по реализации приоритетных направлений НТР необходима разработка механизма государственного регулирования и координации научных исследований, включающего определение укрупненных направлений фундаментальных и прикладных исследований по каждому приоритетному направлению НТР с последующей их детализацией и проведением конкурсного отбора университетов и научных организаций, претендующих на участие в проведении научных исследований, обеспечивая комплексное решение научных проблем каждого приоритетного направления научнотехнологического развития. В дальнейшем это послужит основой создания объединенных научных и экспертных советов, определения головных организаций, формирования консорциумов участвующих организаций, разработки программ и проектов полного инновационного цикла.

Проведенное исследование позволило выделить меры, принимаемые государством по развитию университетской науки и участию вузов в научно-технологическом развитии. Несмотря на значительный нереализованный потенциал высших учебных заведений, который может быть использован в научно-технологическом развитии страны, имеются причины и сдерживающие факторы развития вузовской науки. Сформулированные предложения по их устранению позволят повысить эффективность участия вузов в научно-технологическом развитии как отельного региона, так и страны в целом. 


\section{Библиографический список}

1. Гераскин Н.И., Зайцев К.С., Крючков Э.Ф. Совершенствование норматива соотношения профессорскопреподавательского состава и студентов в федеральных и национальных исследовательских университетах // Университетское управление: практика и анализ. - 2008. - № 5. - С. 39-41

2. Государственное управление научно-технологическим развитием: вопросы теории и практики. Монография / под редакцией Г. П. Белякова. Издание второе. - М.: Изд. «Доброе слово и Ко». - 2020. - 368 с.

3. Гусев А.Б. Современный профиль вузовской науки в России и перспективы его изменения // Наука. Инновации, Образование. - 2012. - Вып. 12. - С. 28-54

4. Иванов В.В., Малинецкий Г.Г. Россия: XXI век. Стратегия прорыва: Технологии. Образование. Наука. М.: ЛЕНАНД, 2016. - 304 с.

5. Как снизить нагрузку университетских преподавателей? [Электронный ресурс]. - URL: https://trv-science. ru/2014/07/kak-snizit-nagruzku-universitetskikh-prepodavateleji/ (дата обращения: 18.10.2021).

6. Клячко Т. Опорные вузы: цели и риски программы // Полит.РУ. 18 апреля 2017. [Электронный ресурс]. - URL: https://ipei.ranepa.ru/ru/sobytiya-ceno/678-opornye-vuzy-tseli-i-riski-programmy (дата обращения: 15.10.2021).

7. Ковтун Е.Н., Родионова С.Е. Нагрузка преподавателей и студентов в новых условиях обучения: принципы планирования и учета // Филология и культура. - 2012. - № 2 (28). - С. 59-63

8. Кудюкин П.М. У российских преподавателей самая большая нагрузка в мире [Электронный ресурс]. - URL: http://netreforme.org/news/pavel-kudyukin-u-rossiyskih-vuzovskih-prepodavateley-samayabolshaya-nagruzka-v-mire/ (дата обращения: 15.10.2021).

9. Мартынова С.В., Ратай Т.В. Вузовская наука в России и мире //Наука. Технологии. Инновации. Экспрессинформация. Институт статистических исследований и экономики знаний Высшей школы экономики [Электронный ресурс]. - URL: https://scientificrussia.ru/articles/vuzovskaya-nauka-v-rossii-i-mire (дата обращения: 18.10.2021).

10. Минобрнауки предлагает новую программу повышения глобальной конкурентоспособности вузов [Электронный ресурс]. - URL: https://tass.ru/obschestvo/8656279 (дата обращения: 17.10.2021).

11. Основы государственной политики регионального развития Российской Федерации на период до 2025 года. Утверждены Указом Президента Российской Федерации от 16.01.2017 № 13. [Электронный ресурc]. - URL: http://www.kremlin.ru/acts/bank/41641 (дата обращения: 15.10.2021).

12. Постановление Правительства РФ от 05.09.2001 № 660 «О Федеральной целевой программе «Интеграция науки и высшего образования России на 2002-2006 годы» [Электронный ресурс]. - URL: https://base.garant. ru/183716/ (дата обращения: 17.10.2021).

13. Постановление Правительства Российской Федерации от 13.05 .2021 № 729 «О мерах по реализации программы стратегического академического лидерства «Приоритет-2030» [Электронный pecypc]. - URL: http://www.consultant.ru/document/cons_doc_LAW_384628/92d969e26a4326c5d02fa79b8f9cf4994ee5633b/ (дата обращения: 18.10.2021).

14. Постановление Правительства Российской Федерации от 13.05 .2021 № 730 «О Совете по поддержке программ развития образовательных организаций высшего образования в рамках реализации программы стратегического академического лидерства «Приоритет-2030» (вместе с «Положением о Совете по поддержке программ развития образовательных организаций высшего образования в рамках реализации программы стратегического академического лидерства «Приоритет-2030»). [Электронный ресурc]. - URL: http://www.consultant.ru/document/cons_doc_LAW_384633/92d969e26a4326c5d02fa79b8f9cf4994ee5633b/ (дата обращения: 17.10.2021).

15. Приказ Министерства образования и науки РФ от 22.12.2014 г. № 1601 «О продолжительности рабочего времени (нормах часов педагогической работы за ставку заработной платы) педагогических работников и о порядке определения учебной нагрузки педагогических работников, оговариваемой в трудовом договоре» [Электронный ресурс]. - URL: https://normativ.kontur.ru/document?moduleId=1 \&documentId=336324 (дата обращения: 15.10.2021).

16. Распоряжение Правительства Российской Федерации от 31.12.2020 № 3697-p [Электронный pecypc]. - URL: http://government.ru/docs/all/131905/ (дата обращения: 15.10.2021).

17. Распоряжение Правительства РФ от 30.04.2014 № 722-р «Об утверждении плана мероприятий (дорожной карты). Изменения в отраслях социальной сферы, направленные на повышение эффективности образования и науки» [Электронный ресурс]. - URL: https://sudact.ru/law/rasporiazhenie-pravitelstva-rfot-30042014-n-722-r/ (дата обращения: 18.10.2021). 
18. Романов Е.В. Нормирование нагрузки преподавателей: проблемы и поиск решений // Университетское управление: практика и анализ. - 2016. - № 104 (4). - С. 64-78

19. Семченков Ю. Вузы vs наука. Что мешает преподавателям заниматься исследованиями // Аргументы и факты [Электронный ресурс]. - URL: https://smol.aif.ru/society/education/vuzy_vs_nauka_chto_meshaet_ prepodavatelyam_zanimatsya_issledovaniyami (дата обращения: 15.10.2021).

20. Триумф амбициозных. Завершен отбор вузов в программу «Приоритет 2030» [Электронный pecypc]. - URL: https://poisknews.ru/science-politic/triumf-ambiczioznyh-zavershen-otbor-vu/ (дата обращения: 17.10.2021).

21. Чуйков А. Для кого нацпроекты - кость в горле? // Аргументы недели. - 2021 - № 38 (782). - С. 10

22. Фальков рассказал о новой программе опорных вузов // РИА Новости. 5 июня 2020 [Электронный ресурс]. URL: https://na.ria.ru/20200605/1572512546.html

23. Эрштейн Л.Б. Чрезмерная нагрузка преподавателей вузов как фактор разрушения высшего образования в России // Вестник ПНИПУ. Социально-экономические науки. - 2021. - № 2. - С. 75-87

24. Ящин А.А., Струкова М. Н. Нормирование и распределение учебной нагрузки: взгляд практика // Университетское управление: практика и анализ. - 2015. - № 6(100). - С. 100-108

25. A. Fursenko, University Research Should Compete with Russian Academy // Science, vol 330, 19 November 2010 , p. 1038 